\title{
Long-distance Pipe Jacking Technology in Municipal Water Supply and Drainage Engineering Construction
}

\author{
Guo Xuemei \\ Inner Mongolia Technical College of Construction \\ Inner Mongolia Hohhot 010050
}

\begin{abstract}
Nowadays, with the sustainable economic development in China, the management of the urban constructional planning in various cities in China has also made great progress and improvement, and urban infrastructure construction is also constantly being improved. To make people's work and life more convenient, municipal projects are also increasing. Municipal water supply and drainage engineering construction in cities are indispensable in urban infrastructure construction. Long-distance drainage often occurs in the construction of water supply and drainage. In order to solve this situation, relevant staff have specially developed a series of long-distance pipe jacking technology and applied it to the construction of municipal water supply and drainage projects, which greatly improves the quality and the efficiency of municipal water supply and drainage projects.
\end{abstract}

\section{Introduction}

China has a large population, which greatly demands urban infrastructure construction. The quality of municipal water supply and drainage is closely connected with people's daily life. It affects people's normal work and life to a great extent, and plays an important role in municipal engineering. For municipal water supply and drainage projects, the most essential part is the management of pipe jacking technology. The application of long-distance pipe jacking technology can greatly improve the quality of municipal water supply and drainage construction and reduce the impact of the traffic and environmental pollution on the city. So we must strengthen the emphasis on long-distance pipe jacking technology.

\section{Long-distance pipe jacking technology}

Before applying the long-distance pipe jacking technology to the construction of municipal water supply and drainage projects, the specific conditions of the construction site, props, and various pipelines need to be investigated clearly, and accurate and detailed analysis must be performed. Customized and exclusive products can be customized based on the results of the analysis of the construction plan. When it is implemented to the actual construction site, the construction planning and execution must be strictly followed during the construction process, and it can ensure that it does not cause any harm to the surrounding environment and the daily life and work needs of the residents to the maximum extent that it can meet the normal progress of the construction.

In municipal water supply and drainage projects, many constructions are carried out by digging the ground to bury pipes to achieve the urban water supply and drainage. Such construction of the drainage project wastes manpower and material resources, but also exists more harms after long-term use. This is a major and difficult issue on the quality to repair. Long-distance pipe jacking technology, as a new technical process, has very significant advantages compared to traditional ground-digging pipe in municipal water supply and drainage projects. The long-distance pipe jacking technology does not require excavation of the ground, and can directly perform construction through the ground building and the road without damaging the base and facilities, reducing the area of the excavated surface. To a large extent, the waste of labour, material and financial resources is reduced, and the amount of construction work is also reduced, the project progress is accelerated, and the work efficiency of construction is greatly improved. During the construction of municipal water supply and drainage projects, the area of the construction space occupied by the long-distance pipe jacking technology is also much smaller than the space occupied by traditional pipe technology, and it will not affect the daily activities, and the noise pollution and environmental pollution are also less, which will not have any impact on the daily lives of the residents in the surrounding communities. Similarly, the construction of long-distance pipe jacking technology will not have a great impact on the normal operation of surrounding infrastructure. With the continuous development of urban construction, in order to bring more convenient life to 
residents, the construction of infrastructure pipes in cities is complicated. Some problems with pipes will have a great impact on people's lives. The construction and application of long-distance pipe jacking technology in municipal water supply and drainage construction can minimize the harms to these pipe facilities. The application of long-distance pipe jacking technology in the construction of municipal water supply and drainage projects can surely bring high quality and efficiency to municipal water supply and drainage projects.

\section{Key points about the application of long-distance pipe jacking technology in municipal water supply and drainage projects}

(I) Application of wall-penetration and water-stilling technology in pipe jacking

In the municipal water supply and drainage construction, in order to prevent water and soil from flowing into the well, yellow clay can be selected as the engineering material, and the method of burying the wall pipe can be effectively implemented. The water-stilling work is effectively implemented, and the bulkhead through the wall pipe can be immediately opened and the constructional tube can be topped. At the same time, the last part of the constructional tube is close to the through-wall tube, it is necessary to stop the related jacking work immediately before the mud enters the hole, and it should be compacted a second time under the corresponding jacking force to avoid ingress of water and soil.

(II) Application of measurement in jacking

Measurement and paying off are carried out during the jacking construction. The relevant centers of urban municipal water supply and drainage pipes and the controlling points of the elevating piles are generally provided by the construction unit. Generally, they are set up on both sides of the pipe jacking pit. The middle line pile must be unified and consistent with the pipe, which can effectively bring inter-flux. The standard of general construction in the pipe jacking work pit should be two to three points, and it should be measured from the construction pit. Usually there may exist some errors, so the amount must be carefully checked, the error of which must be controlled within $5 \mathrm{~mm}$, compared to the implementation of the municipal water supply and drainage jacking project to ensure that the pipeline is placed correctly. The use of advanced scientific and technological facilities and equipment can carry out the measurement, when the related work of the jacking is carried out to the first part of the pipe; the first correction is made for the deviation, and at the same time an effective measurement is performed within $30 \mathrm{~cm}$. After the project is undergone to the soil layer, an effective survey will be carried out at the same time. If there are errors or deviations from the need to ensure adjustment and proofreading. Generally, two adjusting methods can be selected. One is called the Jacking Top-timbering, which is considered to be used when the effect of the excessive excavation adjustment is not obvious during construction. The range of the deviation is considered to be within $2 \mathrm{~cm}$. The combination of excavation and adjusting methods is used to further correct errors. There is also a method called Jacking Corrected Deviation, which has a similar constructional method to the implementation of the top-timbering method. It is to replace the timber with a jack and correct the deviated pipeline. In the implementation of the jacking project, the errors of measurement and correction mainly depend on advanced laser level and electronic-tachometer to ensure accurate measuring frequency, process detection, center-line detection, and related jacking work. Generally, the jacking top-timbering method and the jacking corrected deviation method are used in the jacking.

(III) Application of the technology of anti-dragging of mud in pipe jacking

The longer distance in the jacking construction process will cause greater frictional resistance of the pipeline. In order to reduce the resistance on the outer pipeline, the construction personnel will spray thixotropic mud on the outer pipeline to minimize the jacking resistance and increase work efficiency of jacking construction. Taking a municipal water supply and drainage project in a southern city as an example, the mud-water balanced pipe jacking technology is used in the project. Five pipe jacking wells are designed in the planning, which are J3-J7, with a total length of $1359 \mathrm{~m}$. Here we take the J3-J4 and J6-J7 segments as examples for analysis. The J3-J4 segment has a jacking length of $238 \mathrm{~mm}$, the pipeline needs to be buried at a depth of $8 \mathrm{~m}$, the outer diameter of the pipeline is $242 \mathrm{~mm}$; the J6-J7 segment has a jacking length of $396 \mathrm{~mm}$, the pipeline needs to be buried at a depth of $6.5 \mathrm{~m}$, and the outer diameter of the pipeline is $282 \mathrm{~mm}$, as shown in Table 1:

Table 1: Basic parameters of pipe jacking

\begin{tabular}{|c|c|c|c|}
\hline $\begin{array}{c}\text { Model } \\
\text { number }\end{array}$ & $\begin{array}{c}\text { Outer } \\
\text { diameter of } \\
\text { pipelines }\end{array}$ & $\begin{array}{c}\text { Buried depth } \\
\text { of pipelines }\end{array}$ & $\begin{array}{c}\text { Degree of } \\
\text { jacking }\end{array}$ \\
\hline J3-J4 & $242 \mathrm{~mm}$ & $8 \mathrm{~m}$ & $238 \mathrm{~mm}$ \\
\hline J5-J6 & $242 \mathrm{~mm}$ & $7.5 \mathrm{~m}$ & $399 \mathrm{~mm}$ \\
\hline J6-J7 & $282 \mathrm{~mm}$ & $6.5 \mathrm{~m}$ & $396 \mathrm{~mm}$ \\
\hline
\end{tabular}

In the pipe jacking construction, the penetration resistance at the front end of the pipe joint and the pipe friction force are important in the total jacking force, and the magnitude of the pipe friction resistance can directly determine the jacking force. The pipe diameter, the buried depth of the pipeline, and the contact stress between the pipeline and the soil can all affect the friction of the pipeline. According to the formula for calculating mud-water balanced pipe jacking force (not considering mud-dragging reduction): $\mathrm{F}=\mathrm{F} 0+\mathrm{f} 0 \mathrm{~L}, \mathrm{f} 0=$ $\mathrm{Bc} 2(\mathrm{pe}+\mathrm{pw}+\Delta \mathrm{p}) \pi / 4, \mathrm{f0}=\mathrm{RS}+\mathrm{wf}$ can be calculated The total thrust of J3-J4 is $16019.28(\mathrm{kN})$, and the total thrust of J6-J7 is $30991.65(\mathrm{kN})$.

(IV) Application of interface processing technology in pipe jacking construction

The interface is an indispensable and important part in the construction of the pipe jacking project, and it is also the core part of the municipal water supply and drainage engineering system. Therefore, the construction 
work and related details for the interface are accurately implemented. Before the launch of the related work, the relevant construction requirements and details need to be investigated in time to ensure that the various projects are implemented accurately and to avoid the entry of all unqualified engineering materials.

\section{Key points about the technical management measures for long-distance pipe jacking construction in municipal water supply and drainage construction}

(I) Strictly control the quality of materials and equipment in the construction

With the frequent use of new materials in the construction for urban municipal water supply and drainage construction, irrational distribution of material ratio in the process of urban municipal water supply and drainage occurs. The model has not been correctly evaluated, so engineering materials cannot be scientifically proportioned and controlled, which will cause waste and damage to some engineering materials. This kind of phenomenon will become more serious, and there will be some impacts on the urban municipal water supply and drainage projects. The construction process is accompanied by varying degrees of influence, and will eventually become unreasonable in the cost control. Therefore, it is necessary to complete the necessary controlling system for urban municipal water supply and drainage construction engineering materials, and to efficiently and scientifically control engineering materials to ensure that the project process is scheduled to effectively improve the utilization and use of engineering materials.

(II) Carefully review the drawings and optimize the constructional plan

Urban municipal water supply and drainage construction must be rigorously checked against the relevant drawings to ensure that the construction has a valid basis. In this process, if there are uncertain factors in the drawings, the deadline for rectification and overall improvement is ordered. There is a big difference between the designing drawings and the best planning drawings. It should be corrected immediately. As an important basis for the quality and safety of urban municipal water supply and drainage construction, concrete must have consistent quality standards. Therefore, the construction must undergo a very reasonable scientific research plan, providing a foundation for the safety of urban municipal water supply and drainage construction, reducing the constructional cost. So the construction of urban municipal drainage pipes and the corresponding construction ensure the high quality of urban municipal drainage projects.

(III) Enhance staff's safety awareness and comprehensively improve staff's quality

During the construction of the municipal water drainage, the construction quality of this project should be ensured. Since the engineering construction and economic, administrative, technical and other aspects are inextricably connected, whether the staff of urban municipal drainage pipelines has good execution ability and high working quality affects the main foundation of urban municipal drainage construction, and fully demonstrates the overall focus of details and ability of controlling. Nowadays, the constructional level and developmental progress of urban municipal drainage projects must be continuously improved. It is necessary to comprehensively improve the awareness of safety precautions, responsibility, mission of the relevant operators of municipal drainage pipes and absolute execution, establish a comprehensive scientific and standardized internal promoting mechanism, and build a high-level professional and excellent constructional team of municipal drainage pipeline projects.

\section{Conclusion}

With the continuous development of the social economy, the quality of people's life continues to be improved. In order to meet people's growing needs of life quality, the city's infrastructure is also being constantly improved, and municipal construction has gradually increased. Municipal construction is closely related to people's life and work. Municipal water supply and drainage work can directly affect water supply and drainage in people's daily life. The management of long-distance pipe jacking technology is the most important in determining the quality of water supply and drainage work, which must comprehensively draw the attention of the staff. Long-distance pipe jacking technology can greatly reduce the constructional cost and improve the constructional quality and efficiency, accelerating the overall constructional progress of municipal water supply and drainage projects, ensure the smooth implementation of the construction, and promote the development of urban infrastructure.

\section{References}

1. Liu Chao. Research on technical measures for long-distance pipe jacking construction in municipal water supply and drainage projects [J]. Building Materials and Decoration, 2019 (35): 29-30.

2. Bai Yanjun. Research and analysis of long-distance pipe jacking technology in municipal water supply and drainage construction [J]. Theoretical Research on Urban Construction (Electronic Edition), 2017 (03): 240-242.

3. Zhang Weina. Application of technical measures for long-distance pipe jacking in municipal water supply and drainage projects $[\mathrm{J}]$. Theoretical Research on Urban Construction (Electronic Edition), 2017 (11): 28.

4. Huang Xuefeng, Yang Jingxu, Zhang Yiqiang. Research on long-distance pipe jacking technology in mMunicipal water supply and drainage construction [J]. Theoretical Research on Urban 
Construction (Electronic Edition), 2017 (29): 14.

5. Ming Yongcheng, $\mathrm{Hu}$ Yingwen, Feng Yan.

Exploration of the application of long-distance pipe jacking technology in municipal water supply and drainage construction $[\mathrm{J}]$. Building Materials and Decoration, 2016 (06): 31-32. 